\title{
Spectrophotometric Flow Injection Analysis of Silicates for Manganese
}

\author{
Koichi Oguma, Kazushi Nishiyama and Rokuro Kuroda \\ Laboratory for Analytical Chemistry, Faculty of Engineering, University of Chiba, \\ Yayoi-cho, Chiba 260
}

\begin{abstract}
A flow injection spectrophotometric method has been developed for the determination of manganese in silicate rocks with formaldoxime as a chromogenic reagent. A rock solution is prepared by fusion with a mixture of lithium carbonate and boric acid and subsequent dissolution of the cake in $1 \mathrm{M}$ hydrochloric acid. An aliquot of the sample solution is treated with hydrofluoric and perchloric acids and passed through a cellulose phosphate column to remove polyvalent cations like iron(III) and aluminum(III). A definite portion of the filtrate is injected into the flow system where the manganese-formaldoxime complex allows to be formed and monitored at $452 \mathrm{~nm}$. Nickel is masked with 2-aminoethanethiol by a merging zone technique. The flow injection analysis system permits throughput of 45 samples per hour. The relative standard deviations $(n=10)$ for 0.5 and $2.0 \mathrm{ppm}$ manganese solutions are 0.80 and $0.33 \%$, respectively. The procedure has been applied to a variety of standard silicate rocks of the U.S.Geological Survey and of the Geological Survey of Japan, yielding the results which are in satisfactory agreement with the recommended or reported values.
\end{abstract}

Keywords Silicate analysis, manganese, flow injection analysis, spectrophotometry, formaldoxime

Chemical methods for silicate analysis have fully been developed until now, but are time-consuming and tedious. Use of instrumental methods, particularly Xray fluorescence spectroscopy, inductively coupled plasma spectrometry and atomic absorption spectroscopy, has been gaining major status in silicate analysis both in geochemistry and industries. Recently, flow injection analysis (FIA) has been increasingly used in material analysis, owing to the high throughput and cost performance. This is also the case for silicate analysis for major and minor elements. ${ }^{1}$ We have already developed FIA methods for the determination of titanium ${ }^{2}$, silicon ${ }^{3}$, aluminum ${ }^{4}$, iron ${ }^{4}$, magnesium ${ }^{5}$, calcium $^{6,7}$ and phosphorus. ${ }^{8}$ The work has now been extended to manganese, since it is the element of the ten most commonly occurring constituents in silicate rocks, $\mathrm{SiO}_{2}, \mathrm{TiO}_{2}, \mathrm{Al}_{2} \mathrm{O}_{3}, \mathrm{Fe}_{2} \mathrm{O}_{3}$ (total iron), $\mathrm{MnO}$, $\mathrm{MgO}, \mathrm{CaO}, \mathrm{Na}_{2} \mathrm{O}, \mathrm{K}_{2} \mathrm{O}$ and $\mathrm{P}_{2} \mathrm{O}_{5}$. Since FIA is concerned with liquid samples, we decided to use the same rock sample solution as in our previous works, which is prepared by fusion with lithium metaborate followed by dissolution in dilute hydrochloric acid.

Several papers have already been reported for the determination of manganese in natural waters (spectrophotometric ${ }^{9}$ or catalytic ${ }^{10}$ method used for detection), plant digests (spectrophotometric ${ }^{9}$ or ICP ${ }^{11}$ ), reagents (catalytic) ${ }^{12}$ and food products (catalytic). ${ }^{12}$ Zagatto et $a l . .^{13}$ reported the determination of man- ganese in standard reference rock materials by FIAAAS as an example of applications of "sequential injection" technique. In this paper we describe the spectrophotometric FIA method for manganese with formaldoxime $^{14}$ as a sensitive color reagent.

\section{Experimental}

\section{Reagents}

A manganese standard solution for atomic absorption spectrometry $(0.996 \mathrm{mg} \mathrm{Mn} / \mathrm{ml}$ of $0.1 \mathrm{M}$ nitric acid, Kanto Chemicals) was used. The working standards were prepared by serial dilution of the standard solution with $1 \mathrm{M}$ hydrochloric acid right before use.

A formaldoxime solution $(0.36 \mathrm{M})$ was prepared by dissolving $5 \mathrm{~g}$ of hydroxylamine hydrochloride and 2.5 $\mathrm{ml}$ of $37 \%$ formaldehyde aqueous solution and diluting to $200 \mathrm{ml}$ with water.

An ammonia buffer solution was prepared by dissolving $17.5 \mathrm{~g}$ of ammonium chloride in a mixture of $150 \mathrm{ml}$ of $29 \%$ ammonia water and $100 \mathrm{ml}$ of water.

The chromogenic solution was made up fresh before use by mixing $40 \mathrm{ml}$ of $0.36 \mathrm{M}$ formaldoxime solution and $190 \mathrm{ml}$ of the ammonia buffer solution and diluting to $500 \mathrm{ml}$ with water $(\mathrm{pH}$ of the resulting solution 10.5). 


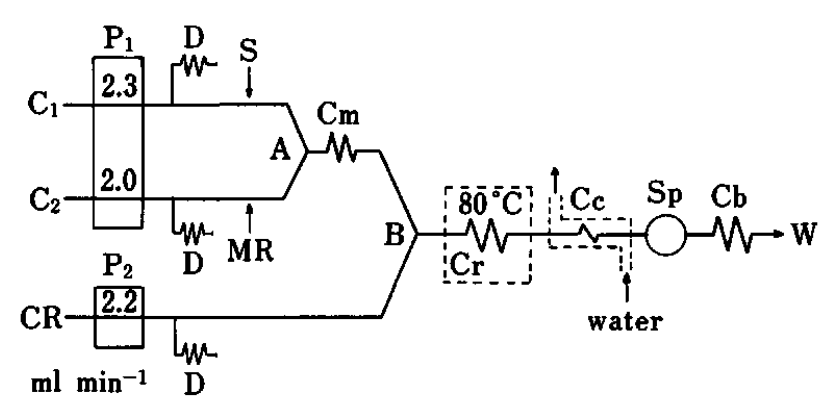

Fig. 1 Block diagram of FIA system. $C_{1}$ :carrier solution ( $\mathrm{M} \mathrm{HCl}$ ); $\mathrm{C}_{2}$ :distilled water; $\mathrm{CR}$ :chromogenic reagent solution ( $0.03 \mathrm{M}$ formaldoxime in $\mathrm{NH}_{4} \mathrm{Cl}-\mathrm{NH}_{4} \mathrm{OH}$ buffer, pH 10.5); $P_{1}, P_{2}$ :pumps; D:damper tubing ( $5 \mathrm{~m}$ ); $\mathrm{S}$ :sample solution $(287 \mu 1)$; MR:1\% 2-aminoethanethiol hydrochloride solution ( $324 \mu \mathrm{l}) ; \mathrm{A}, \mathrm{B}$ : confluence points; $\mathrm{Cm}$ : mixing coil $(1 \mathrm{~m})$; $\mathrm{Cr}$ : reaction coil $(5 \mathrm{~m})$; Cc:cooling coil $(0.7 \mathrm{~m}) ; \mathrm{Sp}$ :spectrophotometer; $\mathrm{Cb}$ : back pressure coil $(4$ $\mathrm{m}$ ); $\mathrm{W}$ : waste. The manifold made of $1.0 \mathrm{~mm}$ i.d. Teflon tubing except for $\mathrm{Cb}(0.5 \mathrm{~mm}$ i.d.).

A masking reagent solution, $1 \%$ aminoethanethiol hydrochloride, was prepared by dissolving $1 \mathrm{~g}$ of the salt in $100 \mathrm{ml}$ of water.

All reagents used were of analytical-reagent grade and distilled and demineralized water was used throughout the work.

\section{Apparatus}

The diagram of the flow injection system for the spectrophotometric determination of manganese is illustrated in Fig. 1. The flow system was assembled from 1-mm bore Teflon tubing and connectors. Two reciprocating pumps were used of double plunger type, SNK DM7M-1074 (Sanuki Kogyo) to pump the carrier solution ( $1 \mathrm{M}$ hydrochloric acid) $\mathrm{C}_{1}$ and distilled water $\mathrm{C}_{2}$ and of single plunger type, Kyowa KHU-52 (Kyowa Seimitsu) to pump the chromogenic reagent solution. A double six-way sample injection valve was used to introduce $287 \mu \mathrm{l}$ of a sample solution and 324 $\mu \mathrm{l}$ of the masking reagent solution simultaneously into the flow system. Color-forming reaction was accelerated through the reaction coil $\mathrm{Cr}$ thermostated at $80^{\circ} \mathrm{C}$ and the product was cooled to room temperature by the coil Cc. A spectrophotometer, Shimadzu UV180 with a flow cell (volume $63 \mu$ l, light-path $20 \mathrm{~mm}$ ) and a data processor Shimadzu Chromatopac C-R1A were jointly used to record the absorbance signal and to process the peak height for calculation.

\section{General procedure}

Decomposition of silicate rocks. Accurately weigh $100 \mathrm{mg}$ of powdered rock sample into a $30-\mathrm{ml}$ capacity platinum crucible and fuse with a mixture of $300 \mathrm{mg}$ of anhydrous lithium carbonate and $300 \mathrm{mg}$ of boric acid for $15 \mathrm{~min}$ at about $1000^{\circ} \mathrm{C}$. Dissolve the melt in $1 \mathrm{M}$ hydrochloric acid with the aid of a magnetic stirrer and then make up the volume exactly to $100 \mathrm{ml}$ with the same acid. Store the resulting solution in a polyethylene bottle.

Determination of manganese. Pipet $10-\mathrm{ml}$ aliquot of the sample solution into a 100-ml Teflon dish. Add 2 $\mathrm{ml}$ of hydrofluoric acid and $0.5 \mathrm{ml}$ of perchloric acid. Evaporate to dryness on a hot plate. Moisten the residue with $0.5 \mathrm{ml}$ of perchloric acid and evaporate again. Take up the residue with $5 \mathrm{ml}$ of $1 \mathrm{M}$ hydrochloric acid with gentle heating. Pass the resulting solution through the cellulose phosphate column ( $1 \mathrm{~g}$ of Whatman P-11, $8 \mathrm{~mm}$ i.d. $\times 70 \mathrm{~mm}$ ) which has been conditioned with $40 \mathrm{ml}$ of $1 \mathrm{M}$ hydrochloric acid. Wash the dish and column with $1 \mathrm{M}$ hydrochloric acid. Reject the early 5-ml fraction of the effluent and collect the following $10-\mathrm{ml}$ fraction directly in a 10-ml capacity volumetric flask. Dilute to mark with the same acid.

Inject an aliquot $(287 \mu \mathrm{l})$ of the effluent and the masking solution $(324 \mu \mathrm{l})$ simultaneously into the carrier solutions, $1 \mathrm{M}$ hydrochloric acid and water, respectively, by the double six-way loop injection valve and mix them in the mixing coil $\mathrm{Cm}$ (See Fig. 1). Make the sample zone meet with the chromogenic reagent solution and allow the manganese-formaldoxime complex formation reaction to be proceeded in the reaction coil $\mathrm{Cr}$, which is immersed in a water-bath $\left(80^{\circ} \mathrm{C}\right)$. Monitor the absorbance (peak height) at 452 $\mathrm{nm}$ against air reference. For calibration, inject a series of manganese standard solutions containing the same amounts of flux as do the sample solutions before and after the sample runs.

\section{Results and Discussion}

\section{Formaldoxime method}

For the spectrophotometric determination of manganese, the permanganate method is most common, but it lacks sensitivity in microchemical analysis. For the present purpose, a more sensitive reagent formaldoxime $\left(0.005 \mu \mathrm{g} \mathrm{cm}-2 / 0.001\right.$ absorbance, $\lambda_{\max }=450$ $\mathrm{nm})^{14}$ was used. Manganese(II) reacts with formaldoxime in alkaline solution to give an orange-red complex possessing the absorption maximum at $\mathbf{4 5 2}$ $\mathrm{nm}(\mathrm{pH} \sim 9.5)$. However, in the alkaline media silicic acid becomes separated as polysilicic acid or metal silicates even in the presence of EDTA or tartaric acid. In the present method, therefore, the evaporation of sample solution with hydrofluoric and perchloric acids was included in the procedure.

In silicate analysis, the formaldoxime method appears not to be well established. Iron(III) seriously interferes with the determination of manganese. Abdullah ${ }^{15}$ claims the overcome of the iron interference with the addition of ascorbic acid, hydroxylammonium chloride and EDTA for silicate rocks and sediments. However, we found that his procedure does not always proceed well in the presence of much iron and 
aluminum. In the previous work ${ }^{7}$ the cellulose phosphate columns was found to show a high selectivity to polyvalent metal ions such as iron(III), aluminum, the rare earths, titanium etc. in dilute hydrochloric acid solution, while alkali metals and divalent cations including manganese pass through the column. Therefore we used the cellulose phosphate column to remove iron as well as polyvalent ions which exhibit the strong hydrolysis in the alkaline media.

Divalent ions including copper(II), nickel(II), cobalt(II), zinc(II), cadmium(II) and mercury(II) can be effectively masked with 2 -aminoethanethiol ${ }^{16}$, the former three elements being the interferents in the aldoxime method. Based on these observations, 2aminoethanethiol hydrochloride was used to achieve the selectivity in manganese determination in the present FIA system.

\section{System development}

In the FIA system, shown in Fig. 1, the sample solution and 2-aminoethanethiol solution allow to be met exactly by the merging zone technique and the mixture merges with the chromogenic reagent solution to yield the manganese-formaldoxime complex.

To obtain the optimum concentration of formaldoxime, its concentration in ammonium buffer carrier solution CR was varied from 0.01 to $0.06 \mathrm{M}$, and the peak heights for 0.5 and $2.0 \mathrm{ppm}$ manganese solutions were measured in the FIA system. As shown in Fig. 2, the absorbance reached the plateau at $0.03 \mathrm{M}$, so that a concentration of $0.03 \mathrm{M}$ was subsequently adopted.

The effect of the temperature was tested with the flow system for two reaction coil lengths as the parameter. For each coil the temperature of the water bath varied from $40^{\circ}$ to $90^{\circ} \mathrm{C}$. As shown in Fig. 3, sensitivity increases with increasing temperature, pas-

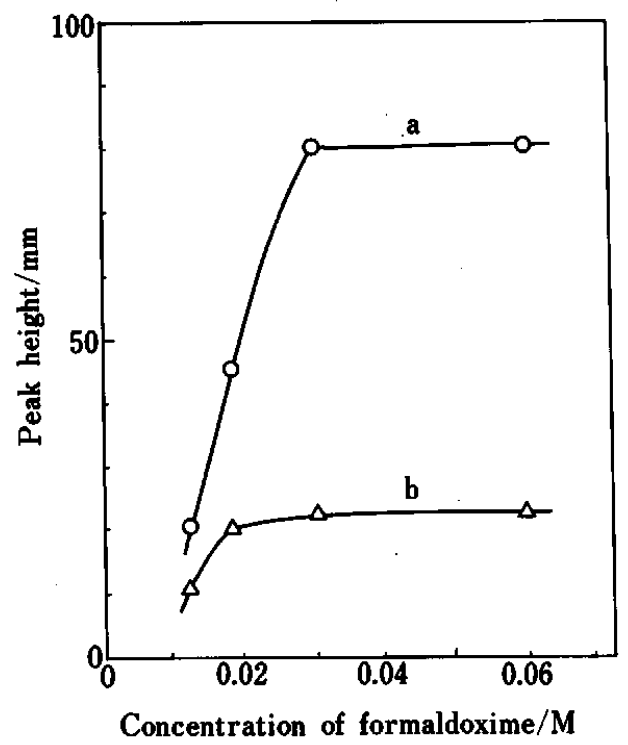

Fig. 2 Effect of formaldoxime concentration on peak height. Manganese : $a, 2.0$ ppm; b, 0.5 ppm. sing a maximum at about $80^{\circ} \mathrm{C}$, then decreases. Increase of both the reaction rate and the dispersion of color slug with increasing temperature may be responsible for the apparent maximum. The $500 \mathrm{~cm}$ reaction coil kept at $80^{\circ} \mathrm{C}$ in the water bath was used throughout.

Flow rates of carrier solutions determine the residence time of a sample slug in the flow system and the residence time reflects the reaction time of analytes.

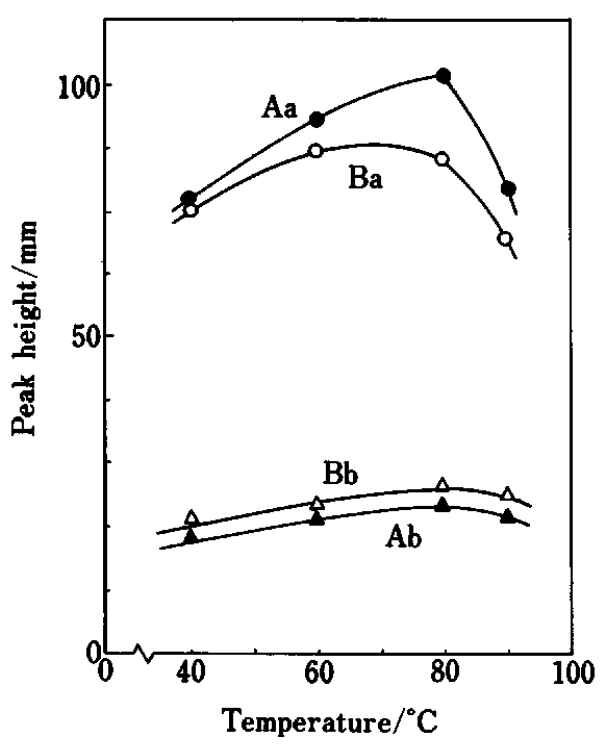

Fig. 3 Effect of reaction coil length and temperature on peak height. Coil length: A, $500 \mathrm{~cm} ; \mathrm{B}, 300 \mathrm{~cm}$. Manganese: a, $2.0 \mathrm{ppm} ; \mathrm{b}, 0.5 \mathrm{ppm}$.

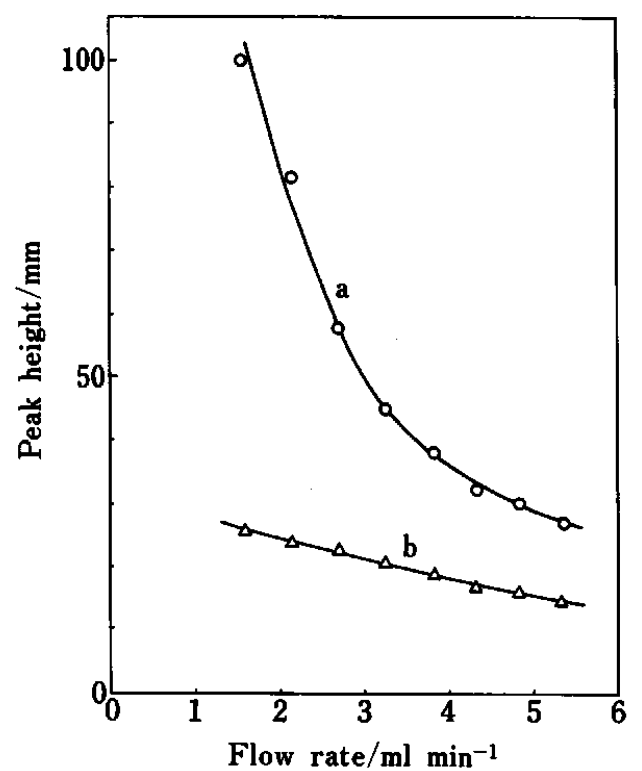

Fig. 4 Effect of flow rate of carrier and chromogenic reagent solutions on peak height. The values on the abscissa represent the average of flow rates of carrier and chromogenic reagent solutions. Manganese: $a, 2.0 \mathrm{ppm} ; \mathrm{b}, 0.5 \mathrm{ppm}$. 
In addition, the dispersion of the sample slug increases with increasing flow rates of carrier solutions. Accordingly, the effect of the flow rates of carrier and chromogenic reagent solutions was examined by keeping their flow rates almost equal and varying them simultaneously from 1.5 to $5.4 \mathrm{ml} / \mathrm{min}$ (Fig. 4). The increase of flow rates resulted in the steep decrease of the peak height for $2.0 \mathrm{ppm}$ manganese solution and the gradual decrease of that for $0.5 \mathrm{ppm}$ manganese solution. Lower flow rates lead to the lower sampling frequency, so that the flow rate of $c a .2 \mathrm{ml} / \mathrm{min}$ was chosen for the carrier and chromogenic reagent solutions as a compromise.

The effect of the sample volume was then examined by injecting the varying volume of 0.5 and $2.0 \mathrm{ppm}$

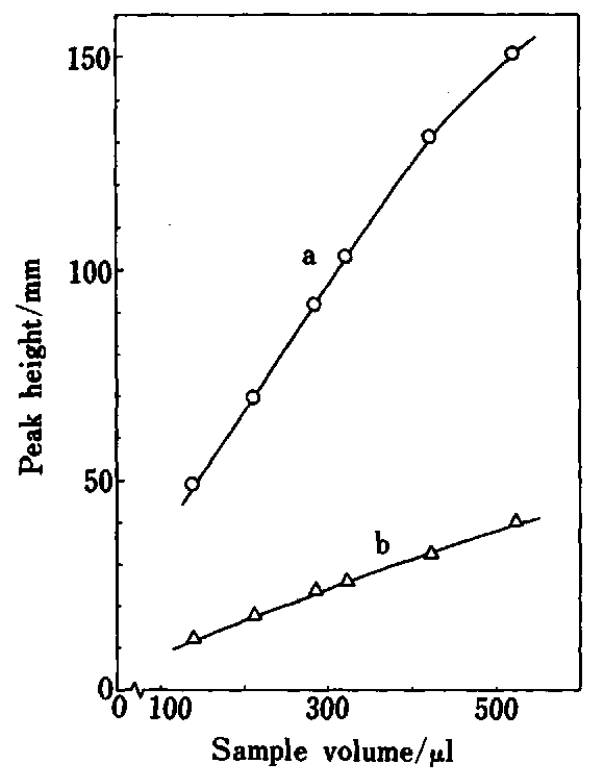

Fig. 5 Effect of sample volume on peak height. Manganese : a, $2.0 \mathrm{ppm} ; \mathrm{b}, 0.5 \mathrm{ppm}$.

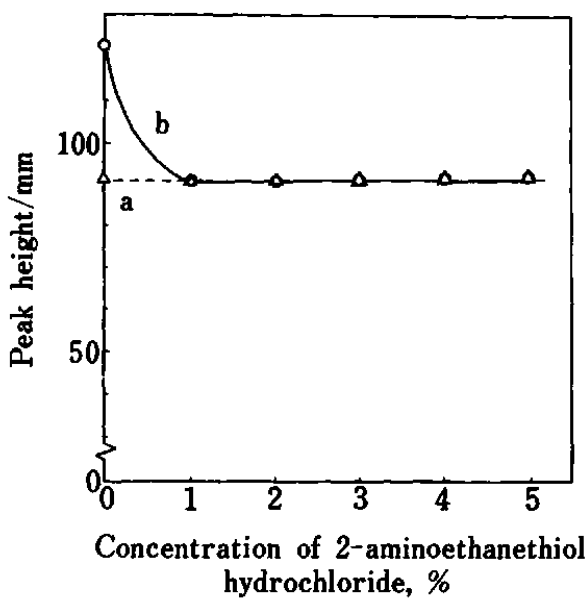

Fig. 6 Masking of nickel with 2-aminoethanethiol hydrochloride. a:2.0 ppm Mn; b:2.0 ppm Mn+2.4 ppm Ni. manganese solutions (Fig. 5). The peak height (sensitivity) increases monotonically with the increasing sample volume. However, the injection of large volumes of sample solution results in decrease of sampling rate. A medium volume $(287 \mu \mathrm{l})$ was usually injected into the FIA system, but, of course, an appropriate volume may be selected depending upon

Table 1 Analysis of U.S.G.S. Standard Rocks

\begin{tabular}{llll}
\hline \multirow{2}{*}{ Sample } & \multicolumn{3}{c}{ MnO, \% } \\
\cline { 2 - 4 } & \multicolumn{2}{c}{ Found } & \multicolumn{1}{c}{ Recommended ${ }^{17}$} \\
\hline AGV-1 & 0.098 & 0.099 & $0.096,0.097,0.10$ \\
BCR-1 & $0.18_{3}$ & $0.18_{4}$ & $0.18,0.18,0.182$ \\
BHVO-1 & $0.16_{8}$ & $0.17_{1}$ & 0.17 \\
DTS-1 & $0.12_{2}$ & 0.11, & $0.11,0.12,0.121$ \\
G-2 & 0.035 & 0.029 & $0.03,0.034$ \\
GSP-1 & 0.043 & 0.040 & $0.04,0.04$ \\
MAG-1 & 0.098 & 0.097 & 0.10 \\
PCC-1 & $0.12_{1}$ & $0.12_{1}$ & $0.119,0.12,0.12$ \\
QLO-1 & 0.093 & 0.089 & 0.09 \\
RGM-1 & 0.039 & 0.040 & 0.04 \\
SCo-1 & 0.049 & 0.050 & 0.05 \\
SDC-1 & $0.12_{2}$ & 0.11, & 0.12 \\
SGR-1 & 0.032 & 0.034 & 0.032 \\
STM-1 & $0.22_{2}$ & $0.22_{3}$ & 0.22 \\
\hline
\end{tabular}

AGV-1 : andesite; BCR-1, BHVO-1 : basalt; DTS-1 : dunite; G-2 : granite; GSP-1 : granodiorite; MAG-1 : marine mud; PCC-1 : peridotite; QLO-1: quartz latite; RGM-1 : rhyolite; SCo-1, SGR-1 : shale; SDC-1 : mica schist; STM-1 : nepheline syenite.

Table 2 Analysis of G.S.J. Standard Rocks

\begin{tabular}{|c|c|c|c|}
\hline \multirow[b]{2}{*}{ Sample } & \multicolumn{3}{|c|}{$\mathrm{MnO}, \%$} \\
\hline & \multicolumn{2}{|c|}{ Found } & $\begin{array}{l}\text { Recommended } \\
\text { or } \text { reported }^{17}\end{array}$ \\
\hline JA-1 & $0.16_{0}$ & $0.15_{3}$ & $0.15^{\mathrm{a}}$ \\
\hline JA-2 & $0.11_{1}$ & $0.11_{0}$ & $0.11^{a}$ \\
\hline JA-3 & $0.10_{7}$ & 0.10 & $0.106^{a}$ \\
\hline JB-1 & $0.15_{3}$ & 0.15 & $0.16^{b}$ \\
\hline JB-2 & 0.21 & $0.22_{2}$ & $0.20^{\mathrm{a}}$ \\
\hline JB-3 & 0.18 & $0.18_{4}$ & $0.16^{\mathrm{a}}$ \\
\hline JF-1 & 0.007 & 0.007 & $0.00^{\mathrm{a}}$ \\
\hline JF-2 & 0.007 & 0.010 & $0.001^{a}$ \\
\hline JG-1 & 0.061 & 0.062 & $0.063^{b}$ \\
\hline $\mathbf{J G}-\mathbf{2}$ & 0.018 & 0.019 & $0.015^{a}$ \\
\hline JG-3 & 0.067 & 0.069 & $0.072^{a}$ \\
\hline$J_{G_{b}-1}$ & 0.18 & $0.18_{8}$ & $0.17^{a}$ \\
\hline JP-1 & 0.096 & 0.097 & $0.12^{\mathrm{a}}$ \\
\hline JR-1 & 0.095 & 0.092 & $0.10^{\mathrm{a}}$ \\
\hline JR-2 & $0.11_{0}$ & $0.11_{3}$ & $0.11^{\mathrm{a}}$ \\
\hline
\end{tabular}

a. Reported value.

b. Recommended value.

JA-1, JA-2, JA-3 : andesite; JB-1, JB-2, JB-3 : basalt; JF-1, JF-2 : feldspar; JG-1, JG-3 : granodiorite; JG-2 : granite; JG J $^{-1}$ : gabbro; JP-1 : peridotite; JR-1, JR-2 : rhyolite. 
the sensitivity desired. In Fig. 6 is shown the effect of 2-aminoethanethiol on the masking of nickel, which is rather abundant in ultramafic rocks. As is shown, the effect of nickel at $2.4 \mathrm{ppm}$ level on the determination of $2.0 \mathrm{ppm}$ manganese can be masked completely by the addition of $1 \%$ or more 2-aminoethanethiol solution with the merging zone technique.

\section{Analytical results}

In order to evaluate the accuracy of the proposed method, the standard rock samples issued by the U. S. Geological Survey (U.S.G.S.) and the Geological Survey of Japan (G.S.J.) were analyzed for manganese, where the same sample solutions as prepared to determine silicon ${ }^{3}$, aluminum ${ }^{4}$, total iron $^{4}$, titanium $^{2}$, calcium $^{6,7}$, magnesium ${ }^{5}$ and phosphorous ${ }^{8}$ were used. The results are listed in Tables 1 and 2, where values of two independent determinations are given. The values are in excellent agreement with the recommended or reported values. The relative standard deviations $(n=10)$ for 0.5 and $2.0 \mathrm{ppm}$ manganese solutions are 0.80 and $0.33 \%$, respectively. The throughput is 45 samples per hour.

\section{References}

1. R. Kuroda, J. FIA, 1, 3 (1984).

2. T. Mochizuki and R. Kuroda, Analyst [London], 107, 1255 (1982).

3. R. Kuroda, I. Ida and H. Kimura, Talanta, 32, 353
(1985).

4. T. Mochizuki and R. Kuroda, Talanta, 29, 699 (1982).

5. K. Oguma, T. Nara and R. Kuroda, Bunseki Kagaku, 35, 690 (1986).

6. H. Kimura, K. Oguma and R. Kuroda, Bunseki Kagaku, 32, T79 (1983).

7. K. Oguma, Y. Kato and R. Kuroda, Bunseki Kagaku, 34, T78 (1985).

8. R. Kuroda, I. Ida and K. Oguma, Mikrochim. Acta [Wien], 1984 I, 377.

9. M. F. Giné, E. A. G. Zagatto and H. Bergamin F:, Analyst [London], 104, 371 (1979).

10. T. Yamane, Anal. Sci., 2, 191 (1986).

11. A. O. Jacintho, E. A. G. Zagatto, H. Bergamin F', F. J. Krug, B. F. Reis, R. E. Bruns and B. R. Kowalski, Anal. Chim. Acta, 130, 243 (1981).

12. S. Maspoch, M. Blanco and V. Cerda, Analyst [London], 111, 69 (1986).

13. E. A. G. Zagatto, M. F. Giné, E. A. N. Fernandes, B. F. Reis and F. J. Krug, Anal. Chim. Acta, 173, 289 (1985).

14. E. B. Sandell, "Colorimetric Determination of Traces of Metals", 3rd ed., Interscience, New York (1959).

15. M. I. Abdullah, Anal. Chim. Acta, 40, 526 (1968).

16. K. Yamaguchi and K. Ueno, Talanta, 10, 1041 (1963).

17. K. Govindaraju, Geostandards Newslett., Vol. VIII, Spec. Issue (1984).

18. A. Ando and S. Terashima, "Major chemical composition of GSJ rock reference materials-igneous rock series", Geological Survey of Japan (1986).

(Received April 20, 1987) (Accepted May 6, 1987) 